purposes. Four persons were injured and the others experienced severe bruises. The real cause of the catastrophe is to be investigated officially by M. Giffard, the celebrated French engineer. At present it is supposed that the band of india-rubber which acts as a spring gave way under influence of the frosty weather.

THE Italian Geographical Society (the Daily Nezus Roman correspondent telegraphs) held its first monthly meeting of the winter session on Sunday. Capt. Barrattieri read the report of the Society's expedition to the Tunisian Sahara last June. It gave interesting details of the journey to Gabes, to the 1sland of Gerba, and to other islands, described the country minutely, and proved the impossibility of the French project for connecting the Sahara with the Mediterranean by canal. The next paper, that of Deputy Caperio, on the latest explorations of Lake Victoria, dwelt on the importance of investigating the sources of the Nile between the mountains parallel to the coast and Lake Victoria. This was the task of the Italian expedition.

IN illustration of some remarks in the address of the president, Mr. H. R. Robson, of the Scottish Institution of Engineers and Shipbuilders, the number of the Transactions of that Society just published contains a large and carefully executed plate exhibiting a section of the Sub-Wealden bore-hole to the depth of 940 feet.

No. 166 of the Notizblatt des Vereins fïr Erdkunde zu Darmstadt and des Mittel heinischen geologischen Vereins contains a detailed résume of the meteorological observations made at Darmstadt during 1874 , accompanied with a neat and cleanly constructed diagram showing the daily and monthly results; and also the max'. mum and minimum temperatures, rainfall, and fog at six stations, during September 1875 , in the Grand Duchy of Hesse. Among the many points detailed in the summary for Darmstadt may be noted the dates of the last and the first snow in the course of the year, the last and first frost, the last and first frost-day, mean temperature being $32^{\circ}$ or lower; the number of frost-days each month, and of summer-days, temperature being $77^{\circ} \circ$, or higher, and the particular days on which thunder and other weatherphenomena occurred. From November to June the ozone was greatly in excess during the night, but during the other months the excess occurred during the day. Among other matters, there is an interesting table of the mortality during September last from various diseases, at thirteen towns in the Grand Duchy. The deaths from diarrhoea alone, which amounted to sixtytwo, were a"sixth of the whole. This high diarrhœa deathrate, which is three times greater than that of London during the same season, and the unequal manner in which these deaths, as well as deaths from phthisis, convulsions, and brain diseases, are distributed among the thirteen towns, suggest the desirableness of an inquiry into their sanitary conditions.

AT recent meetings of the Executive Committee of the British Pharmaceutical Conference, grants amounting in all to 75 l., were made to a number of chemists for the purpose of obtaining material to enable them to carry on "scientific researches into the nature and properties of certain substances used in pharmacy.

THE additions to the Zoological Society's Gardens during the past week include a Yellow-fronted Amazon (Chrysotis ochrocephala) from Demerara, presented by Mrs. Sproston; a Tree Sparrow (Passer montanus), two Mountain Linnets (Linaria Aavirostris), European, purchased; a West African Python (Python seba) from West Africa, presented by Mr. W. H. Berkeley.

AT the annual meeting on the $4^{\text {th }}$ inst. of the Huddersfield Naturalists' Society, the Secretary read a satisfactory report. The number of members is 134 , the finances are in a flourishing condition, and during the past year twenty-two papers have been read.

\section{ON SOME PROPERTIES OF GALLIUM}

IN a communication just made to the French Academy, $M$

Lecoq de Boisbatudran states that he has succeeded, after considerable labour, in obtaining salts of gallium sufficiently pure to give, in addition to the gallium spectrum, only fain traces of the zinc lines $Z n \propto 144.62$ and $Z_{n} \gamma I_{50} 05$.

After adding a few facts regarding mixtures of gallium and zinc, he proceeds to examine certein reactions of the pure salts.

r. The electric spectrum of chloride of gallium, a little concentrated, is very brilliant. The line $4 \mathrm{I} 7$ is much brighter than the line 404. The author did not observe any other line attributable to gallium; there certainly are none of notable intensity, under the conditions. The colour of the spark in chloride of gallium is a beautiful clear violet.

2. In the gas flame he got only the line Ga a 4I7, and very faint and fugitive, even with a salt which gave a brilliant electric spectrum.

3. The chloride and the sulphate of $\mathrm{Ga}$ are precipitated by $\mathrm{NH}_{3}$, but the precipitate is redissolved, in great part, in an excess of $\mathrm{NH}_{3}$. Taking up with $\mathrm{HCl}$ the portion not dissolved by $\mathrm{NH}_{3}$, and recommencing the operation, all the $\mathrm{Ga}$ is promptly obtained in ammoniacal solution.

4. An ammoniacal solution of sulphate or chloride of $\mathrm{Ga}$ is precipitated in the cold or hot state by an excess of acetic acid. The liquor must be extremely diluted.

5. The chloride and the sulphate of $\mathrm{Ga}$ are not precipitated in the cold state by the acid acetate of ammonia, but the reaction takes place on heating.

6. The sulphate of $\mathrm{Ga}$ is soluble in a 60 per cent. alcohol solution.

8. A salt was obtained which the author believes to be am. moniaco-gallic alum ; though, in default of sufficient quantity, he was unable to analy se it or measure the angles.

9. The alum of $\mathrm{Ga}$ is soluble in cold water, but, on heating, the salt is decomposed, and the liquor becomes greatly troubled.

Io. This alum is not decomposed in the hot state by water with addition of acetic acid.

II. It crystallises very easily in cubes and octahedra, present. ing exactly the aspect of ordinary alum; its solution, evaporated under the microscope, also presents the characteristic changes of known alums.

12. The crystals do not act on polarised light (between two Nicols giving extinction).

13. A small crystal was kept some time under a layer of water, then transferred to a slightly supersaturated solution of alumino-ammoniacal alum; it immediately increased in it, and caused the crystallisation of the liquor.

14. With ammonia in excess, the alum of Ga behaves like the other salts of this metal ; a portion of the oxide is precipitated, the other portion remains in solution.

15. The very acid solution of $\mathrm{Ga}_{2} \mathrm{Cl}_{6}$ is precipitated by the yellow prussiate.

I6. The ammoniacal solution of sulphate of $\mathrm{Ga}$ is decomposed by the voltaic current. Metallic gallium is deposited on the platinum plate serving as negative electrode. The positive electrode is covered, at the same time, with a whitish pellicle, which is easily detached from the platinum, and is insoluble in a large excess of $\mathrm{NH}_{3}$. In a first operation I $6 \mathrm{mgr}$. of $\mathrm{Ga}$ were deposited in $4 \mathrm{~h} .30 \mathrm{~m}$. On a platinum plate of about 185 square millimetres surface. The surface of the positive electrode was about 877 sq. $\mathrm{mm}$. The battery consisted of five bichromate couples (zincs: $17 \mathrm{~cm} . \times 10 \mathrm{~cm}$.) coupled in tension. The author presented to the Academy a specimen weighing $3.4 \mathrm{mgr}$; ; t was deposited in $5 \mathrm{~h}$. $40 \mathrm{~m}$. on a surface of about 123 to $\mathrm{I} 24 \mathrm{sq} . \mathrm{mm}$. The positive electrode $877 \mathrm{sq} . \mathrm{mm}$. ; the current furnished by ten bichromate elements (as above) coupled in tension.

I 7. Electrolytic gallium forms a very adherent layer; it is hard; it is polished with difficulty by friction with an agate burnisher. A better polish is obtained by strong compression under the burnisher; the metal thus acquires great brightness, and appears whiter than platinum. When the electric current and the relative dimensions of the electrodes are properly regu. lated, the gallium presents a beautiful dull surface of silvery white, finely granulated, and interspersed with small brilliant points, which the microscope shows to be crystals.

18. Gallium, deposited on a platinum plate, is not much oxidised during washing in cold or boiling water, nor on being dried in free air raised to about $200^{\circ}$. It decomposes water acidulated with $\mathrm{HCl}$ in the cold state, and more rapidly in the hot state, with a brisk liberation of hydrogen, 
The salts of Ga which M. Lecoq de Boisbaudran has used in his researches, have been from the blend of Pierrefitte; he has, however, found the new metal in other ores of zinc, and notably in a transparent blend from Santander. He believes $\mathrm{Ga}$ will be met with in all blends. The Ga he extracted from the blends comes really from these minerals, and not from metallic zinc.

The author's last researches have confirmed the rarity of gallium in blend. The extreme sensibility of the spectral reaction led him even to over-estimate the quantities obtained "I do not think I exaggerate," he remarks, "in saying that in my frrst observation I possessed at the most $1 \frac{1}{10} \pi$ of a milligramme of the new substance dissolved in a very small drop of liquid. The spectral analysis of so small a quantity of matter would have been impracticable before the considerable reduction I made gin the dimensions of the apparatus for obtaining electric spectra, and without using very small sparks.

"If, as I suppose, there is no error as to the nature of my alum of $\mathrm{Ga}$, the existence of this salt fixes the atomicity of the new element, and attributes to its oxide the same chemical function as that of alumina. The oxide of gallium, then, will be written $\mathrm{Ga}_{2} \mathrm{O}_{3}$."

The author, in conclusion, refrains, for the present, from discussing the theoretical considerations raised in a recent note by M. Mendeleeff. Questions of the kind have long interested him; but he thinks it very probable that without the particular method followed in the present research, neither M. Mendeleeff's theories nor his own would soon have led to the discovery of gallium.

\section{SCIENTIFIC SERIALS}

American Fournal of Science and Art, November.-The original articles in this number are:-O On the variation in the strength of a muscle, by F. E. Nipher.-Studies on magnetic distribution, by H. A. Rowland. This, Part I., is on linear distribution, and the scope is indicated by the titles of the sections: I. Preliminary Remarks; 2. Mathematical Theory ; 3. Experimental Methods for Linear Distribution; 4. Iron Rods magnetised by induction; 5. Straight Electro-magnets and permanent Steel Magnets; 6. Miscellaneous Applications.- Gistivation and its terminology, by Asa Gray. - A note in relation to the mass of meteoric iron that fell in Dickson County, Tenn., 1835 , by J. L. Smith.-- Specific gravity balance, by Roswell Parish. The object of this is to deternine the specific gravities of minerals, and other solids heavier than water, without the ue of exact weights and without mathematical computation.-A paper on Southern New England, by Prof. Dana, - - Iowa county meteor and it: meteorites, by N. R. Leonard.-On the post-Pliocene fossils of Sankoty Head, Nantuck Island, by A. E. Verrill. This article, referring to the paper by Desor and Cabot (Geol. Soc. Lond., I 849), purports to correct some matters of detail in that paper, and raises the number of known species from seventeen to sixty, of which a list is given. - In the short articles under "Scientific Inielligence" are :-Arithmetical relations between the atomic weighis; Evidence of glacial action on the summit of Mrunt Washington; Discovery of the horns of an extinct species of ox in Ohio.--The two following reports are noticed On the geology and resources of the region in the vicinity of the 49th parallel from the Lake of the Woods to the Rocky Mountains; A reconnaissance of the Black Hills of Dakota made in the summer of $1874 .-$ In an appendix Prof. O. C. Marsh contributes a paper on the Odontornithes, or birds with teeth. After recapitulating facts he has already contributect, he gives this classification:- Sub-class, ODONTORNATHES: A. Teeth in sockets; vertebra biconcave; sternum with keel; wings well developed; order, Ichthyornithes. B. Teeth in grooves; vertebræ as in recent birds; sternum without keel ; wings rudimentary; order, Udontolce. There are two plates in illustration of this paper.

Zeilschsift der Oesterreichischen Gesellschaft für Meteorologie, Oct. 15. - In the concluding part of his article on the higher atmospheric strata, Dr. Hellmann gives the following results:(2) Moisture : time of maximum, upper station, 4.30 P.M.; lower station, 5.43 P.M. ; time of rrinimum : upper station, $73 \mathrm{~A} . \mathrm{M}$ lower station, 7.30 A.M. The daily variation at the upper station is only haif that at the lower station. From a table of relative humidity we learn that the air is much moister at the upper station and removed by an almost constant quantity from saturation. In the morning and evening the lower air is the moister, at midday the upper. (3) Wind. Easterly winds were less prevalent at the summit than at the foot of Mount Washington, in the proportion of $I: 2$. It is now well ascertained that the wind at ordinary heights increases in strength daily from early morning till about 2 P.M., and then decreases until about 9 P.M. Herr Hellmann was surprised to discover a variation exactly contrary to this to hold on the summit. In fact, the least velocity occurs about I P.M., the greatest after 12 at night; while at the foot the usual variations were followed. Dove explains the generally observed increasing velocity in the morning in our climate by the combined action of a large mass of heated air ascending in the east, and the prevalence of westerly winds. In the evening the heated area would lie westward, the two influences would oppose each other and the wind would decrease in velocity. Similarly the diminution of velocity from early morning to mid.day at great heights may be caused by the overflow westward of the air heated in an area east of the station opposing the prevailing west wind, and the acceleration in the afternoon by the overfow eastward from the heated area now in the west adding itself to the west wind. In agreement with this view is the fact, shown by observations on the Rigi, that velocity in summer is least about mid-day, much greater in the early morning and late evening, and in winter on the contrary, in harmony with the variations at low levels. The greatest observed velocity was ninety-six miles an hour. While this storm blew aloft a calm reigned below. But is it not likely that a current was drawn upwards by it? We have no instruments to register vertical currents. With respect to the relation of temperature to height, clearly it cannot be simply formulated, and will differ according to the altitude at which the daily ascending current flows off laterally. Clouds. There was more cloud and fog at the summit about midday than at other times, and, roughly speaking, the amount of cloud varied inversely as that below during the daytime.

Memorie della Societa degli Spettroscopisti Italiani, March, contains a table by Father Secchi, showing the number of protuberances and spots viewed, and the number of days on which observations were made during each revolution of the sun from April 1871 to March 1875, in all forty-two revolutions. The number of protuberances or spots seen during each revolution, divided by the number of days, gives an average for each day; this in 1871 was about 26 for protuberances and 100 for spots, and decreases graduailly down to 5.45 for protuberances and 18.8 for spots, in March last. Drawings of the chromosphere for January, February, and March, by Secchi and Tacchini, also accompany this number.

May.-A paper by Prof. Bredichin, on spectroscopic observations of the sun, referring to the relation between spots and prominences, or the latter being the cause of the former. A long series of observations by Prof. Tacchini, from February to June 1873 , showing the positions on the sun in which prominences containing magnesium or giving the 1474 line wer. seen. The maximum number of positions in which magnesium was observed for any one day was sixty, and the same number for the 18\%4 line.-Prof. Pisati contributes a paper on the theories of electro-static inducion.

June. - Prof. Tacchini writes on a method of determining the angles of position of spots and facula. In this case the image of the sun is thrown by the eye-piece of the telescope on to a screen on which is a divided circle, with which the image of the sun coincides. - Father Secchi contributes a paper on the solar prominences observed from April 1871 to June 1875. Accompanying this paper are tables showing the number of prominences in each ten degrees of solar latitude, together with their heights and sizes.

July.-A note on the presentation of a medal to Prof. $H$. Draper by the United States Government for his assistance in preparing for the Transit of Venus. - Observations of the positions in which prominences containing magnesium occurred during July 1873 , by Prof, 'Tacchini.-Drawings of chromosphere during March and April 1874, by Secchi and Tacchini.

August. - A continuation of table by Tacchini, showing positions on sun where prominences containing magnesium occurred during August and September 1873.--Prof. Tacchini writes on observation of the Perseids of last August, in which he gives the mean radiant point as $2 \mathrm{~h}$. $50 \mathrm{~m}$. and $+53^{\circ} 8^{\prime} \cdot 6$.

Vicrhandiungen der k. k. grologischen Reichsanstalt. Vienna, Sept. 30.-In this number Dr. Schimper describes the geological conditions of the district of Arrho, in Abyssinia, and a curious apparently volcanic phenomenon met with there. The district is a cleft-crossed plain near (and below the level ol) the 